\title{
Cast Intermetallic Alloys by SHS Under High Gravity
}

\author{
V. Sanin*, D. Andreev, D. Ikornikov and V. Yukhvid \\ Institute of Structural Macrokinetics and Materials, Chernogolovka, Moscow Region, 142432 Russia \\ Pilot-scale series of cast $\mathrm{Ti}-\mathrm{Al}, \mathrm{Ti}-\mathrm{Al}-\mathrm{Nb},(\mathrm{Ni}, \mathrm{Co}, \mathrm{Mn}) \mathrm{Al}_{x}, \mathrm{Ni}-\mathrm{Cr}-\mathrm{Al}-\mathrm{Si}-\mathrm{C}$, and $\mathrm{Co}-\mathrm{V}-\mathrm{Al}-\mathrm{Si}-\mathrm{C}$ alloys were \\ produced by thermit-type SHS under high gravity for their potential use as heat-resistant materials, master alloys, \\ precursors for catalysts, etc.
}

PACS: 81.05.Bx, 81.05.Mh, 81.20.Ka

\section{Introduction}

Intermetallides are known for their high strength, heat/corrosion resistance, and unique friction properties. Nickel-, cobalt-, and titanium-based intermetallic alloys are being used as superalloys for gas-turbines, aerospace jets, pressure vessels, heat-resistant coatings [1], and multi-purpose catalysts $[2,3]$.

As is known, a wide variety of refractory materials, including intermetallics, can be fabricated by the methods of so-called SHS metallurgy which is a combination of Self-propagating High-temperature Synthesis (SHS) and metallothermy [4-6]. Since the combustion temperatures are extremely high $(2500-3500 \mathrm{~K})$, the combustion products (alloys and oxides) appear in the their liquid state.

In this communication we report on the synthesis of some new Ni-, Co-, and Ti-based cast alloys by SHS metallurgy in conditions of normal gravity and in the field of centrifugal forces.

\section{Experimental}

The overall scheme of thermit-like SHS reactions can be represented as follows:

$$
\begin{aligned}
& \left(\mathrm{O}_{x_{1}}+\mathrm{O}_{x_{2}}+\mathrm{O}_{x_{3}}+\ldots+\mathrm{O}_{x_{n}}\right)+\mathrm{R} \\
& \quad \rightarrow \text { polymetallic alloy }+\mathrm{R}_{k} \mathrm{O}_{l}+Q
\end{aligned}
$$

where $\mathrm{O} x_{i}$ stands for the oxides of $\mathrm{Ni}, \mathrm{Co}, \mathrm{Ti}, \mathrm{Cr}, \mathrm{Nb}$, Mo, W, V, Mn, etc., $\mathrm{R}$ is metal reducer (Al, Ti), and $Q$ the reaction heat.

Combustion was carried out in cylindrical graphite moulds the inner surface of which was lined with a layer of $\mathrm{Al}_{2} \mathrm{O}_{3}$ ) or $\mathrm{Al}_{2} \mathrm{O}_{3}-\mathrm{Cr}_{2} \mathrm{O}_{3}$ (in case of $\mathrm{Ni}$ or $\mathrm{Co}$ ) or $\mathrm{Y}_{2} \mathrm{O}_{3}$ (in case of Ti). Experiments were carried out in the centrifugal machine shown in Fig. 1. The ingots with a weight of $1.1-1.0 \mathrm{~kg}$ could be produced in the range $1-1000 \mathrm{~g}$, where $g$ is free fall acceleration. The sketch of process chart is given in Fig. 2.

\footnotetext{
* corresponding author; e-mail: svn@ism.ac.ru
}

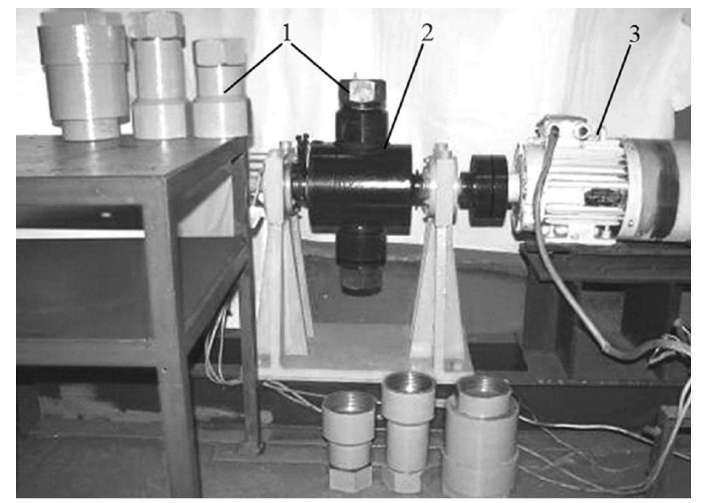

Fig. 1. Overall view of centrifugal facility: (1) changeable chamber with refractory mould, (2) rotor, (3) electric motor.

The extent of product splashing $\left(\eta_{s p}\right)$ was determined as $\left[M_{0}-\left(M_{1}+M_{2}\right)\right] 100 \%$, where $M_{0}$ is the green mixture weight and $M_{1}, M_{2}$ are the weights of the metallic and oxide phases, respectively.
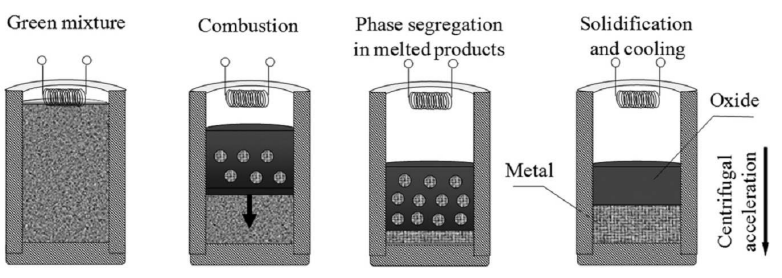

Fig. 2. The sketch of process chart.

After synthesis, the metallic and oxide casts were cut into pieces and characterized by chemical analysis, XRD (DRON-3), and SEM/EDS (Zeiss Ultra plus). 


\section{Results and discussion}

\section{1. $T i-A l$ and $T i-A l-N b$ alloys}

Gamma-titanium aluminides are ideal candidates for use in high-performance gas turbine blades. The use of titanium aluminide would provide a $50 \%$ weight reduction of turbine components compared to current Ni-based alloys. However, advances in the development of TiAl alloys $[7,8]$ are held back by the lack of a successful process for their manufacture at appropriate quality and acceptable cost. Existing processes for fabrication of titanium aluminides are multistage and time-consuming. In this context, elaboration of new cost-effective methods or simplification of existing ones seems to be of current importance.

We explored the feasibility of preparing $\mathrm{Ti}-50 \mathrm{Al}$ and $\mathrm{Ti}-46 \mathrm{Al}-8 \mathrm{Nb}$ ingots (indicated are at. \%) as precursors for subsequent vacuum arc melting (VAM).

The overall reaction schemes can be written as

$$
\begin{aligned}
& \nu_{1}\left(\mathrm{TiO}_{2}+\mathrm{Al}\right)+\nu_{2}\left(\mathrm{CaO}_{2}+\mathrm{Al}\right) \\
& \quad \rightarrow \nu_{3} \mathrm{Ti}_{x} \mathrm{Al}_{y}+\nu_{4}\left(\mathrm{Al}_{2} \mathrm{O}_{3}-\mathrm{CaO}\right) \\
& \nu_{1}\left(\mathrm{TiO}_{2}+\mathrm{Nb}_{2} \mathrm{O}_{5}+\mathrm{Al}\right)+\nu_{2}\left(\mathrm{CaO}_{2}+\mathrm{Al}\right) \\
& \quad \rightarrow \nu_{3} \mathrm{Ti}_{x} \mathrm{Nb}_{y} \mathrm{Al}_{z}+\nu_{4}\left(\mathrm{Al}_{2} \mathrm{O}_{3}-\mathrm{CaO}\right)
\end{aligned}
$$

A prerequisite for SHS casting materials is that the attained combustion temperature $T_{c}$ must be higher than the melting point $T_{m}$ of combustion products: $T_{c}>T_{m}$. The data of thermodynamic calculations (Fig. 3) show that the $T_{a d}$ values for both selected mixtures are insufficient for the purpose: $T_{a d} \leq T_{m}$. In the presence of unavoidable heat losses, the real combustion temperature is still lower. Thermodynamic analysis of many systems has shown that, in order to elevate $T_{c}$, we can add some amount of $\mathrm{CaO}_{2}+\mathrm{Al}$ mixture that would react to provide the supply of additional reaction heat $Q_{1}$ to the system:

$$
\mathrm{CaO}_{2}+\mathrm{Al} \rightarrow \mathrm{Al}_{2} \mathrm{O}_{3}+\mathrm{CaO}+\mathrm{Q}_{1} .
$$

As follows from Fig. 3, the addition of $\mathrm{CaO}_{2}+\mathrm{Al}$ mixture gives a marked increase in $T_{a d}$, which opens up a way to combustion synthesis of cast aluminides. For $\nu_{2}>$ 0.2 , all the products can be expected to appear in the form of melt. In addition, the selected mixture $\left(\mathrm{CaO}_{2}+\right.$ $\mathrm{Al})$ yields the products which are inert toward the target products. With increasing $T_{c}$, the amount of gaseous products (suboxides, Al vapor) can increase, which may lead to melt splashing. As a result, an optimum for $\nu_{2}$ can be expected to happen within the range $0.2-0.4$.

With increasing $\nu_{2}$, the splash of melted material becomes more and more pronounced. In preliminary experiments under normal conditions $[P=0.1 \mathrm{MPa}$ (air), $T_{0}=293 \mathrm{~K}, 1 \mathrm{~g}$ ], we determined the optimal values of $\nu_{2}$ for each product-forming mixture. Within these ranges of $\nu_{2}(0.3-0.45)$, dense titanium aluminides could be prepared in a high yield (good phase segregation). The overall view of the samples burned at different centrifugal acceleration $a$ is shown in Fig. 4. It follows that the degree of phase separation grows with increasing $a$. The samples

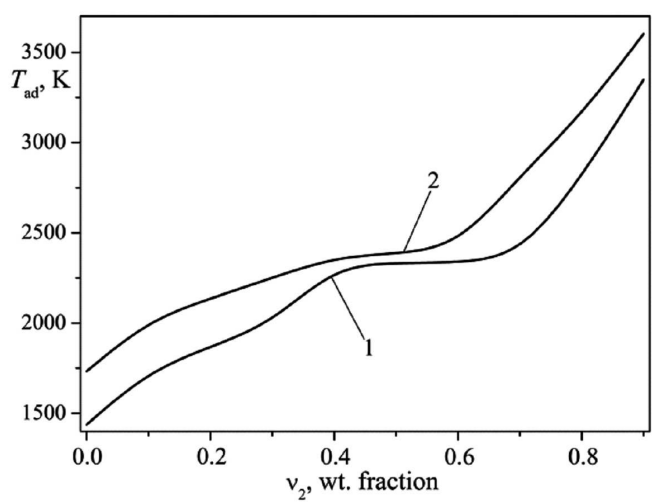

Fig. 3. Calculated values of $T_{a d}$ vs. relative amount $\nu_{2}$ of energy-producing $\left(\mathrm{CaO}_{2}+\mathrm{Al}\right)$ mixture added to (1) $\mathrm{Ti}+\mathrm{Al}(50)$ and $(2) \mathrm{Ti}+\mathrm{Al}(46)+\mathrm{Nb}(8)$ mixtures (indicated are at. \%).

obtained at $a=300-1000 \mathrm{~g}$ represented a cylindrical ingot with readily separated metallic and oxide layers.

Varying the relative amount of components in the product-forming mixture, we can change the chemical composition of ingots and thus come to the target composition $\mathrm{Ti}-\mathrm{Al}(46)-\mathrm{Nb}(8)$.

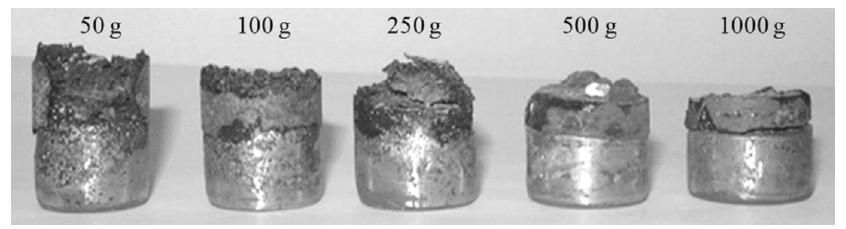

Fig. 4. Effect of $a$ on the macrostructure of products (overall view after extraction from a mould).

It has been found that the $\mathrm{Ti}$ and $\mathrm{Nb}$ contents of the ingots grow with increasing $a$ (Table). This was associated [9] with the squeeze of reaction zone and concomitant increase in the yield of these elements.

\section{TABLE}

Elemental composition of ingots obtained at different $a$ for $\mathrm{Ti}-\mathrm{Al}(46)-$ $\mathrm{Nb}(8)$ (at. \%).

\begin{tabular}{l|c|c|c|c}
\hline \hline \multirow{2}{*}{ Elements } & \multicolumn{3}{|c}{ Composition (at. \%) } \\
\cline { 2 - 5 } & $50 \mathrm{~g}$ & $250 \mathrm{~g}$ & $500 \mathrm{~g}$ & $1000 \mathrm{~g}$ \\
\hline $\mathrm{Ti}$ & 48.8 & 47.8 & 45.8 & 45.9 \\
$\mathrm{Nb}$ & 7.9 & 8.0 & 8.2 & 8.4 \\
$\mathrm{Al}$ & 42.7 & 43.5 & 45.2 & 45.5 \\
others (B, C) & 0.6 & 0.7 & 0.8 & 0.2
\end{tabular}

Despite a high $\mathrm{Nb}$ content, XRD data exhibit no Nbcontaining intermetallics but show the presence of $\gamma^{\prime}$ TiAl and $\alpha_{2}-\mathrm{Ti}_{3} \mathrm{Al}$. All the peaks are shifted toward greater interplanar distances, which can be associated with formation of a solid solution of $\mathrm{Nb}$ in the TiAl lattice. According to the literature data, the solubility of 
$\mathrm{Nb}$ in TiAl attains a value of 11 at. \% (in our case, 8 at. $\%)$.

The absence of nitrogen-containing products can be due to protection of the melt from nitridation with atmospheric nitrogen by the slag layer formed on the melt surface.

The XRD data confirm the prediction of thermodynamic calculations about the inertness of the products formed upon combustion in the $\mathrm{CaO}_{2}+\mathrm{Al}$ system towards the melt. The aluminides contained no Cacontaining products even for $\nu_{2}>50 \%$.

The grain size of products was found to decrease with increasing $a$. The alloys obtained at 300-400 $\mathrm{g}$ exhibited a high heterogeneity (liquation), see Fig. 5.

\section{2. (Ni, Co, Mn)Al alloys}

Deep oxidation of $\mathrm{CO}$ and hydrocarbons as well as $\mathrm{NO}_{x}$ reduction is the key problem in purification of exhaust gases from internal combustion engines and effluent gas flows from different industrial enterprises. To date, the catalytic systems for purification of exhaust gases normally contain precious noble metals such as $\mathrm{Pt}, \mathrm{Rh}$, and $\mathrm{Pd}$. Meanwhile, an alternative to the above systems can be $[2,3]$ intermetallides of $3 d$ metals.

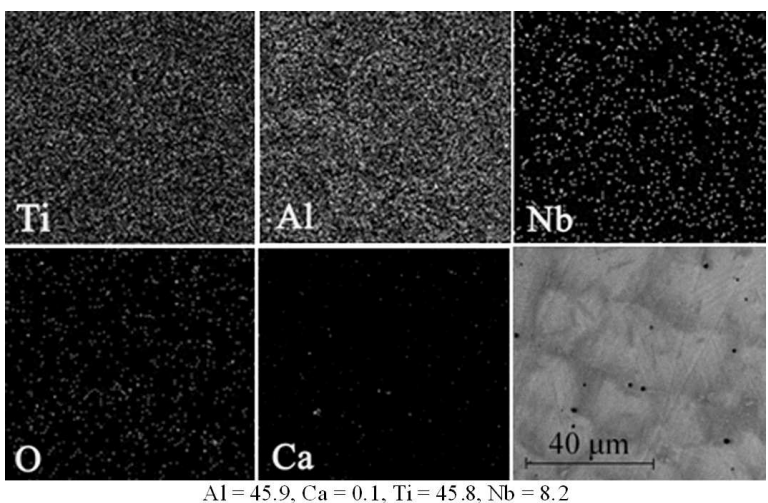

Fig. 5. Distribution of elements and the EDS data for the ingot surface, nominal alloy composition: $\mathrm{Ti}-$ $\mathrm{Al}(46)-\mathrm{Nb}(8)$.

We carried out the following three reactions:

$$
\begin{aligned}
& \mathrm{NiO}+\mathrm{Co}_{3} \mathrm{O}_{4}+\alpha \mathrm{Al} \rightarrow \mathrm{NiAl}_{x}-\mathrm{CoAl}_{x}+\mathrm{Al}_{2} \mathrm{O}_{3} \\
& \mathrm{NiO}+\mathrm{MnO}_{2}+\alpha \mathrm{Al} \rightarrow \mathrm{NiAl}_{x}-\mathrm{MnAl}_{x}+\mathrm{Al}_{2} \mathrm{O}_{3} \\
& \mathrm{NiO}+\mathrm{Co}_{3} \mathrm{O}_{4}+\mathrm{MnO}_{2}+\alpha \mathrm{Al} \\
& \rightarrow \mathrm{NiAl}_{x}-\mathrm{CoAl}_{x}-\mathrm{MnAl}_{x}+\mathrm{Al}_{2} \mathrm{O}_{3}
\end{aligned}
$$

Preliminary experiments under normal gravity $(1 g)$ with variation in $\alpha$ have shown that the reactions are selfsustainable for $\alpha>0.4$. With increasing $\alpha$, the density of the metallic phase decreases, as well as the burning velocity $U$. As a result, phase separation has no enough time for completion. The degree of product splashing $\eta_{s p}$ is defined by a ratio of characteristic times of phase separation $\left(t_{s}\right)$ to cooling time $\left(t_{c}\right)$ which is a function of combustion temperature $\left(T_{c}\right)$ and gravity $(a=g)$, see Fig. 6 .
Burning velocity $(U)$ and weight loss $\left(\eta_{s p}\right)$ as a function of $\alpha$ for $\mathrm{NiO}+\mathrm{MnO}_{2}+\alpha \mathrm{Al}$ mixtures at $a=400 \mathrm{~g}$ are given in Fig. 6. It follows that, for $a>400 \mathrm{~g}$, the combustion limits can be extended up to $\alpha>0.6$ in order to obtain ingots with a high $\mathrm{Al}$ content.

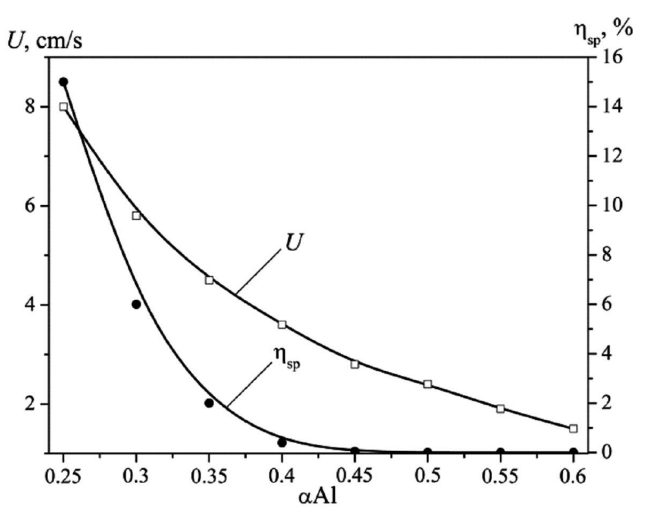

Fig. 6. Burning velocity $(U)$ and weight loss $\left(\eta_{s p}\right)$ as a function of $\alpha$ for $\mathrm{NiO}+\mathrm{MnO}_{2}+\alpha \mathrm{Al}$ mixtures at $a=400 \mathrm{~g}$.

Sample macrostructure markedly depends on the degree of phase segregation. At low overloads (below $100 \mathrm{~g}$ ), a sintered composition with a cermet structure is formed, the matrix is formed by an oxide phase within which metallic drops are uniformly distributed. For $a>400 g$, two-layer products with a close-cut separation of layers are obtained. When phase segregation is complete, a lower metallic layer is easily separated from the upper one by a slight mechanical action.

Figure 7 shows the microstructure of some $\mathrm{Ni}-\mathrm{Mn}-$ $\mathrm{Al}$ intermetallides. The distribution of components is seen to be fairly uniform. The XRD data for $\mathrm{Ni}-\mathrm{Mn}-$ $\mathrm{Al}$ intermetallide revealed the presence of $\mathrm{NiAl}_{3}, \mathrm{Ni}_{2} \mathrm{Al}_{3}$, $\mathrm{Mn}_{4} \mathrm{Al}_{11}, \mathrm{Mn}_{5} \mathrm{Al}_{8}$, and $\mathrm{Mn}_{6} \mathrm{Al}$, in $\mathrm{Ni}-\mathrm{Co}-\mathrm{Mn}-\mathrm{Al}$, the $\mathrm{CoAl}_{3}$ phase was observed in addition to the abovementioned ones. In Figs. 7c, 8c, dark gray areas correspond to manganese aluminides while light gray and gray areas, to nickel and cobalt aluminides.
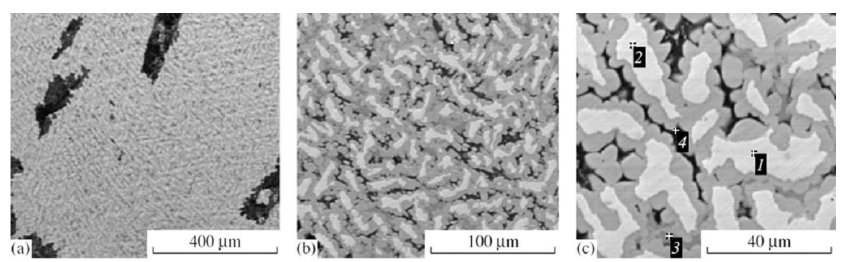

Fig. 7. Microstructure and local composition of $\mathrm{Ni}-$ $\mathrm{Mn}-\mathrm{Al}$ intermetallides (wt \%): (1) $40.4 \mathrm{Al}, 0.3 \mathrm{Mn}, 59.3$ $\mathrm{Ni}$, (2) $40.9 \mathrm{Al}, 0.3 \mathrm{Mn}, 58.8 \mathrm{Ni}$, (3) $62.6 \mathrm{Al}, 22.6 \mathrm{Mn}$ $14.8 \mathrm{~N}$, (4) $90.4 \mathrm{Al}, 1.7 \mathrm{Mn}, 7.9 \mathrm{Ni}$.

Figure 9 shows the microstructure of different surface areas of $\mathrm{Ni}-\mathrm{Mn}$ and $\mathrm{Ni}-\mathrm{Co}-\mathrm{Mn}$ alloys. Their surface is highly eroded. On some sample sections, we can easily 


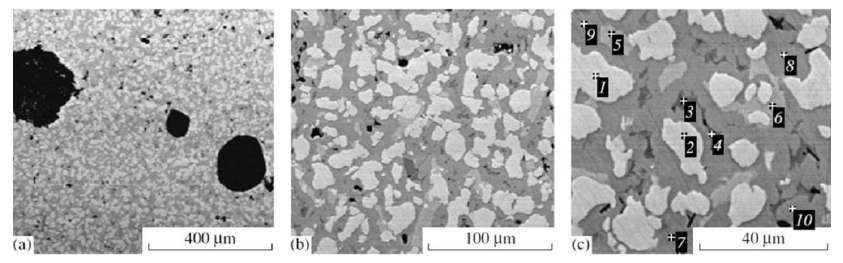

Fig. 8. Microstructure and local composition of $\mathrm{Ni}-$ Co-Mn-Al intermetallides (wt \%): (1) $40.0 \mathrm{Al}, 4.5 \mathrm{Co}$, $55.5 \mathrm{Ni}$, (2) $40.9 \mathrm{Al}, 5.1 \mathrm{Co}, 54.0 \mathrm{Ni}$, (3) $62.0 \mathrm{Al}, 22.4$ Mn, 2.2 Co, $13.4 \mathrm{Ni}$, (4) 62.2 Al, 21.9 Mn, 1.7 Co, 14.2 $\mathrm{Ni}$, (5) $50.3 \mathrm{Al}, 1.1 \mathrm{Mn}, 10.8 \mathrm{Co}, 37.8 \mathrm{Ni}$, (6) $51.4 \mathrm{Al}$ $1.2 \mathrm{Mn}, 11.2 \mathrm{Co}, 36.2 \mathrm{Ni}$, (7) 55.2 Al, 4.0 Mn, 4.4 Co, $36.4 \mathrm{Ni}$, (8) $56.4 \mathrm{Al}, 0.4 \mathrm{Mn}, 3.9 \mathrm{Co}, 39.3 \mathrm{Ni}$, (9) 56.4 Al, $1.2 \mathrm{Mn}, 3.2 \mathrm{Co}, 39.2 \mathrm{Ni}$, (10) $55.5 \mathrm{Al}, 0.3 \mathrm{Mn}, 3.8$ Co, $40.4 \mathrm{Ni}$.

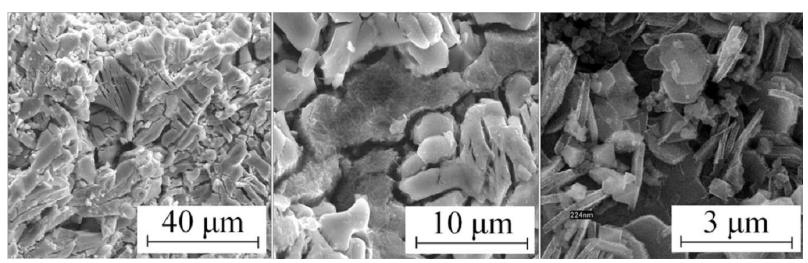

Fig. 9. Microstructure of the surface of (a) Ni-Mn and (b) $\mathrm{Ni}-\mathrm{Co}-\mathrm{Mn}$ catalysts.

see a thick layer of nanosized fibers 1-2 $\mu \mathrm{m}$ long and 80-90 nm thick. However, the formation of this structure does not yield a significant increase in the specific surface area owing to its relatively small portion in the material bulk. A microanalysis of such sections showed that the oxygen content of this layer is significant. These nanofibers seem to be the oxide or metal oxide formations.

The samples of Ni-Co alloy exhibited catalytic activity but their stability was far from satisfactory [10, 11].

\section{3. $\mathrm{Ni}-\mathrm{Cr}-\mathrm{Al}-\mathrm{Si}$ and $\mathrm{Co}-\mathrm{V}-\mathrm{Al}-\mathrm{Si}$ master alloys}

In this case, we carried out the following reactions:

$$
\begin{aligned}
& \mathrm{NiO}+\mathrm{Cr}_{2} \mathrm{O}_{3}+\mathrm{Al}+\mathrm{Si} \\
& \quad \rightarrow \mathrm{Ni}-\mathrm{Cr}-\mathrm{Al}-\mathrm{Si}+\alpha \mathrm{Al}_{2} \mathrm{O}_{3} \\
& \mathrm{Co}_{3} \mathrm{O}_{4}+\mathrm{V}_{2} \mathrm{O}_{5}+\mathrm{Al}+\mathrm{Si} \\
& \quad \rightarrow \mathrm{Co}-\mathrm{V}-\mathrm{Al}-\mathrm{Si}+\alpha \mathrm{Al}_{2} \mathrm{O}_{3}
\end{aligned}
$$

Relevant thermodynamic data presented in Fig. 10 show that the formation of cast alloys in these systems is quite possible.

The microstructures of $\mathrm{Co}-\mathrm{V}-\mathrm{Al}-\mathrm{Si}$ and $\mathrm{Ni}-\mathrm{Cr}-\mathrm{Al}-$ Si alloys synthesized under normal and high gravity $(1000 \mathrm{~g})$ are presented in Figs. 11 and 12. An increase in $a$ is seen to improve the yield and quality of resultant product.

\section{Conclusions}

Pilot-scale series of cast $\mathrm{Ti}-\mathrm{Al}, \mathrm{Ti}-\mathrm{Al}-\mathrm{Nb},(\mathrm{Ni}, \mathrm{Co}$, $\mathrm{Mn}) \mathrm{Al}_{x}, \mathrm{Ni}-\mathrm{Cr}-\mathrm{Al}-\mathrm{Si}-\mathrm{C}$, and $\mathrm{Co}-\mathrm{V}-\mathrm{Al}-\mathrm{Si}-\mathrm{C}$ alloys were

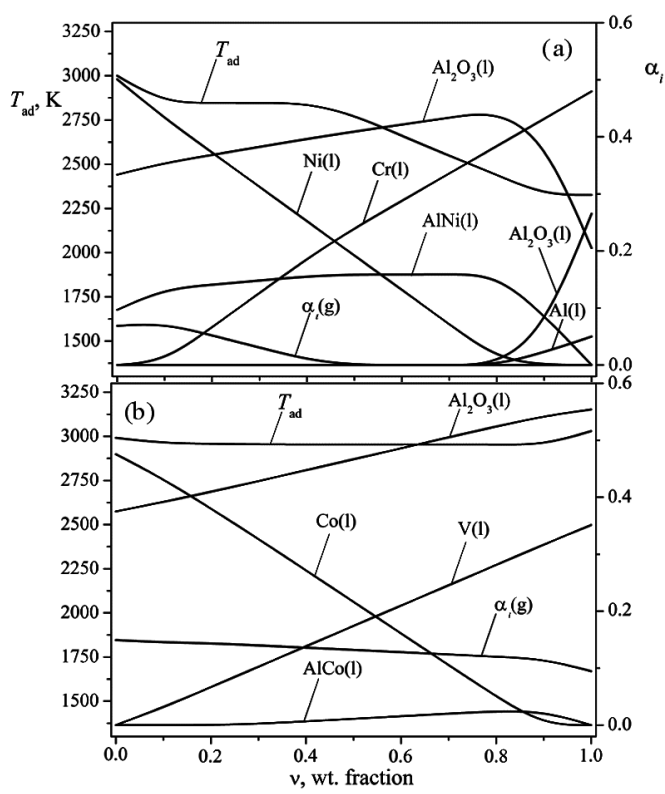

Fig. 10. The results of thermodynamic analysis for the reactions: (a) $(1-\nu)(3 \mathrm{NiO}+\mathrm{Al})+\nu\left(\mathrm{Cr}_{2} \mathrm{O}_{3}+2 \mathrm{Al}\right) \rightarrow$ $\mathrm{Ni}-\mathrm{Cr}-\mathrm{Al}+\mathrm{Al}_{2} \mathrm{O}_{3}$ and $(\mathrm{b})(1-\nu)\left(3 \mathrm{Co}_{3} \mathrm{O}_{4}+8 \mathrm{Al}\right)+$ $\nu\left(3 \mathrm{~V}_{2} \mathrm{O}_{5}+10 \mathrm{Al}\right) \rightarrow \mathrm{Co}-\mathrm{V}-\mathrm{Al}+\mathrm{Al}_{2} \mathrm{O}_{3}$.

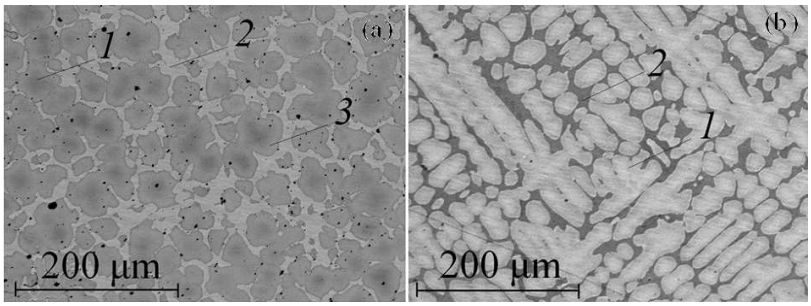

Fig. 11. Microstructure and local composition of $\mathrm{Co}^{-}$ $\mathrm{V}-\mathrm{Al}-\mathrm{Si}$ alloys synthesized under (a) normal and (b) high gravity $(1000 \mathrm{~g}$ ), wt \%: (a) (1) $76.9 \mathrm{Co}, 11.1$ $\mathrm{V}, 10.8 \mathrm{Al}, 1.2 \mathrm{Si},(2) 82.4 \mathrm{Co}, 11.9 \mathrm{~V}, 4.2 \mathrm{Al}, 1.5 \mathrm{Si}$,

(3) $1.2 \mathrm{Co}, 51.2 \mathrm{Al}, 47.6 \mathrm{O}$, (b) (1) $83.4 \mathrm{Co}, 10.5 \mathrm{~V}, 1.3$ $\mathrm{Al}, 4.8 \mathrm{Si},(2) 74.5 \mathrm{Co}, 13.9 \mathrm{~V}, 1.7 \mathrm{Al}, 9.9 \mathrm{Si}$.
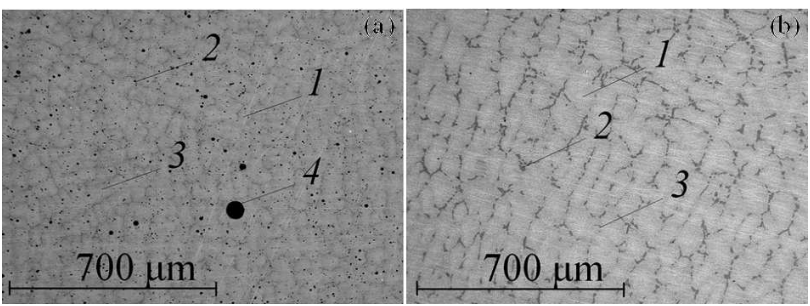

Fig. 12. Microstructure and composition of $\mathrm{Ni}-\mathrm{Cr}-\mathrm{Al}-$ $\mathrm{Si}$ alloys synthesized under (a) normal and (b) high gravity (1000 g), wt \%: (a) (1) $74.40 \mathrm{Ni}, 18.1 \mathrm{Cr}, 6.3$ Al, 1.2 Si, (2) $73.2 \mathrm{Ni}, 17.8 \mathrm{Cr}, 8.5 \mathrm{Al}, 0.5 \mathrm{Si}$, (3) 74.7 $\mathrm{Ni}, 16.3 \mathrm{Cr}, 8.6 \mathrm{Al}, 0.4 \mathrm{Si}$, (4) $0.4 \mathrm{Ni}, 44.1 \mathrm{Al}, 55.5 \mathrm{O}$, (b) (1) $77.4 \mathrm{Ni}, 13.7 \mathrm{Cr}, 8.1 \mathrm{Al}, 0.8 \mathrm{Si}$, (2) $71.9 \mathrm{Ni}, 10.5$ Cr, 14.3 Al, 3.3 Si, 75.3 Ni, 14.3 Cr, 8.0 Al, 2.4 Si. 
produced by thermit-type SHS under high gravity. Synthesized materials can find their potential application as heat-resistant materials, master alloys, precursors for catalysts, etc.

\section{Acknowledgments}

This work was supported by the Russian Foundation for Basic Research (project nos. 10-03-91219 and 10-0300316).

\section{References}

[1] Superalloys II, Ed. C.Y. Sims, Wiley, New York, 1987.

[2] A.J. Smith, L.O. Garciano, Tran Tam, M.S. Wainwright, Ind. Eng. Chem. Res. 47, 1409 (2008).

[3] B.W. Hoffer, E. Crezee, F. Devred, P.R.M. Mooijman, W.G. Sloof, P.J. Kooyman, A.D. van Langeveld, F. Kapteijn, J.A. Moulijn, Appl. Catal. A 253, 437 (2003).

[4] A.G. Merzhanov, Adv. Mater. 4, 294 (1992).
[5] N.P. Lyakishev, Yu.L. Pliner, G.F. Ignatenko, S.I. Lappo, Alyuminotermiya (Aluminothermy), Metallurgiya, Moscow 1978.

[6] V.I. Yukhvid, V.N. Sanin, A.G. Merzhanov, in: Processing by Centrifugation, Ed. L.L. Regel, Kluwer, Amsterdam 2001, p. 185.

[7] Y.W. Kim, F.H. Foes, in: High Temperature Aluminides and Intermetallics, Ed. S.H. Wang, TMS, Warrendale 1990, p. 465.

[8] R. Boyer, G. Welsch, E.W. Collins, Materials Properties Handbook: Titanium Alloys, ASM International, Ohio 1994, p. 797.

[9] D.E. Andreev, V.N. Sanin, V.I. Yukhvid, Int. J. SHS 14, 219 (2005).

[10] V.N. Sanin, D.E. Andreev, E.V. Pugacheva, S.Ya. Zhuk, V.N. Borshch, V.I. Yukhvid, Inorg. Mater. 45, 777 (2009).

[11] V.N. Borshch, E.V. Pugacheva, S.Ya. Zhuk, D.E. Andreev, V.N. Sanin, V.I. Yukhvid, Dokl. Akad.Nauk 419, 775 (2008). 